\title{
Development and Validation of Methods of Quantitative Determination of Loratadine in Tablets
}

\author{
L. S. Logoyda*, O. B. Polyauk, D. B. Korobko and M. B. Chir ${ }^{1}$ \\ Department of Pharmaceutical Chemistry, Ternopil State Medical University \\ named after I. Ya. Horbachevsky, Ternopil, Ukraine; lilya-19@mail.ru \\ 'Department of Research Forensic Centre at the Ministry of Internal Affairs of \\ Ukraine in Ternopil Region, Ternopil, Ukraine
}

\begin{abstract}
Methods for the quantitative determination of loratadine tablets by differential spectrophotometry and photo-colorimetry have been developed. During the procedure parameters (range of application methods, stability, specificity, robasnist, convergence, internal laboratory accuracy (precision), accuracy, reproducibility) have been considered. The results indicate that the method photo-colorimetry has not met modern criteria for analytical methods for quantitative determination of parameters such as stability, accuracy and linearity, so other validation parameters (robasnist, convergence and interlaboratory precision) have been determined only by spectrophotometric methods. It is found that the technique of quantitative determination of loratadine by differential spectrophotometry is accurate, correct, reproducible and linear, to determine its suitability for use in pharmaceutical analysis.
\end{abstract}

Keywords: Differential Spectrophotometry, Loratadine Tablets, Photo-Colorimetry, Quantitative Detection, Validation

\section{Introduction}

Loratadine $-\mathrm{H}_{1}$-antihistamines second generation antihistamine non sedative effective long-term action to rapid and severe allergic effect. It does not affect the central nervous system, does not exhibit anticholinergic and sedative action does not cause addiction. Also detects and anti vasoconstrictive effect on the nasal mucosa, prevents spasm of the bronchi, has a membrane stabilizing effect and so on. Its use to quickly achieve remission and relapse prevention spending allergic diseases, especially in children ${ }^{1}$ and in treatment of complex allergic disease, such as asthma and allergic rhinitis, allergic conjunctivitis, atopic dermatitis, etc ${ }^{2}$. Pharmaceutical market in Ukraine has many mono-drugs and some combination drugs that contain loratadine ${ }^{3}$.
The problem of the development of new methods for the quantitative determination of active pharmaceutical ingredients in the finished product was and remains relevant and at present there. Due to the large quantities of organic solvents for the test, complexity and sustainability sample preparation and methods in general, the high cost of reagents and instruments - will increase the costs for analyzing both the laboratory quality control of medicines and in the Central Laboratory of pharmaceutical companies. Therefore, the development of new, more advanced and simple in execution methods of analysis of drugs remains a topical issue of modern pharmacy.

As we know from literature sources ${ }^{4}$, the substance is loratadine sufficiently studied in terms of pharmaceutical analysis: for its developed methods of identification and quantitative determination. Quantitative determination

${ }^{*}$ Author for correspondence 
of loratadine in medicines and methods of differential spectrophotometry and photo-colorimetry literature practically are not described. Therefore, the above mentioned methods we have chosen to quantify loratadine tablets.

\subsection{The Purpose of the Work}

Development and validation of quantitative determination of loratadine tablets by photo-colorimetry and differential spectrophotometry.

\section{Experimental Section}

\subsection{Research Methods}

The study was conducted on five samples loratadine tablets domestic producers «Zdorovja» (series 31012), «Lekchim» (series 100512), «Farmak» (series 330912), «Arterium» (series 40612), «Darnitsa» (series 200712). In this series using analytical equipment: UV Carry -spectrophotometer 50, electronic scales AVT-120-5DM; measuring vessel class, appropriate reagents that meet the requirements of SPU and pharmacopoeia standard sample (CRS) loratadine (certificate number 11 / 1-243 of 02.12.13), acquired in the State enterprise «Ukrainian scientific center pharmacopoeia quality medicines».

\subsection{Sample Preparation}

Preliminary tests we have developed methods of identification of loratadine in tablets, one of which was based on qualitative reactions - the formation of hydroxamic acids ${ }^{5,6}$. Loratadine as the ester can form hydroxamic acid by reaction equation:

$$
\mathrm{RCOOC}_{2} \mathrm{H}_{5}+\mathrm{NH}_{2} \mathrm{OH} \rightarrow \mathrm{RCONHOH}+\mathrm{C}_{2} \mathrm{H}_{5} \mathrm{OH}
$$

Hydroxamic acid ions $\mathrm{Fe}^{3+}$ forms a complex compound of blue-red color, whose intensity can be measured spectrophotometrically:

$3 \mathrm{RCONHOH}+\mathrm{FeCl}_{3} \rightarrow(\mathrm{RCONHO})_{3} \mathrm{Fe}+3 \mathrm{HCl}$.

Spectrophotometric method of quantitative determination of loratadine tablets by differential spectrophotometry below:

\subsubsection{Test Solution}

The exact weight powdered tablets equivalent to 0.00104 millimole loratadine is dissolved in methanol $R$ and filtered into volumetric flask, add $0.5 \mathrm{ml}$ of 2 mole hydroxylamine hydrochloride $\mathrm{R}$ in methanol $\mathrm{R}, 0.5 \mathrm{ml}$ solution of 0.09 millimole potassium hydroxide $R$ in alcohol $R$, heated and cooled with shaking. The resulting solution is acidified with 6 drops of 2 mole hydrochloric acid $\mathrm{R}$, add $0.2 \mathrm{ml}$ of 0.26 millimole iron (III) chloride R1 diluted 10 times; appears bluish-red color. The resulting solution is adjusted methanol $R$ to the mark and immediately measure the optical density.

\subsubsection{Reference Solution}

0.00104 millimole loratadine CRS dissolved in methanol $R$ in a volumetric flask, add $0.5 \mathrm{ml}$ of 2 mole hydroxylamine hydrochloride $\mathrm{R}$ in methanol $\mathrm{R}, 0.5 \mathrm{ml}$ solution of 0.09 millimole potassium hydroxide $R$ in alcohol $R$ is heated and cooled with shaking. The resulting solution is acidified with 6 drops of 2 mole hydrochloric acid R, add $0.2 \mathrm{ml}$ of 0.26 millimole iron (III) chloride R1 diluted 10 times; appears bluish-red color. The resulting solution is adjusted methanol to the mark and immediately measure the optical density.

\subsubsection{Compensation Solution}

0.00104 millimole loratadine CRS dissolved in methanol $R$ in a volumetric flask, add $0.5 \mathrm{ml}$ solution of 0.09 millimole potassium hydroxide $R$ in alcohol $R$, heated and cooled with shaking. The resulting solution is acidified with 6 drops of 2 mole hydrochloric acid $\mathrm{R}$. The resulting solution is adjusted methanol to the mark and immediately measure the optical density. Absorbance of the test solution and reference solution is measured at $530 \mathrm{~nm}$ wavelength regarding compensation solution. Calculate the content of loratadine in a single tablet, in g, based on the average tablet weight, based on the declared loratadine content of CRS loratadine. Content loratadine tablets, g, calculated by formula (3.1).

$$
\mathrm{X}=\frac{\mathrm{A}_{\mathrm{x}} \cdot \mathrm{m}_{\mathrm{o}} \cdot \mathrm{m}_{\mathrm{av}}}{\mathrm{A}_{\mathrm{o}} \cdot \mathrm{m}}
$$

Validation methods performed in accordance with the requirements of HFCs under the standard procedure of validation techniques quantification of medicines [7].

\section{Results}

During the procedure considered the following parameters: range of application methods, stability, specificity, 
Table 1. The study of the stability analytical solution for the quantitative determination by photo-colorimetry of loratadine in tablets

\begin{tabular}{cccccccccc}
\hline \multirow{2}{*}{$o$} & \multicolumn{4}{c}{ Term stability studies, $\mathrm{t}, \mathrm{min}$} & & Average & $\mathrm{RSDt} \%$ & $\Delta \mathrm{t}, \%$ & $\max \boldsymbol{\delta}, \%$ \\
\cline { 2 - 6 } & $\mathbf{2 , 5}$ & $\mathbf{5}$ & $\mathbf{1 0}$ & $\mathbf{1 5}$ & $\mathbf{3 0}$ & & & & \\
\hline Ast & 0,4840 & 0,4817 & 0,4753 & 0,4613 & 0,4437 & 0,4678 & 3,416 & 7,28 & 1,52 \\
Ax & 0,4787 & 0,4712 & 0,4660 & 0,4557 & 0,4393 & 0,4641 & 3,336 & 7,11 & \\
\hline
\end{tabular}

Table 2. The study of the stability analytical solution for the quantitative determination by spectrophotometry of loratadine in tablets

\begin{tabular}{|c|c|c|c|c|c|c|c|c|}
\hline \multirow[t]{2}{*}{ № } & \multicolumn{5}{|c|}{ Term stability studies, $t$, min } & \multirow[t]{2}{*}{ Average } & \multirow{2}{*}{$\begin{array}{c}\text { RSDt, } \\
\%\end{array}$} & \multirow[t]{2}{*}{$\max \delta, \%$} \\
\hline & $\mathbf{0}$ & 15 & 30 & 45 & 60 & & & \\
\hline Ast & 0,4117 & 0,4117 & 0,4130 & 0,4130 & 0,4140 & 0,4123 & 0,311 & 1,52 \\
\hline $\mathrm{Ax}$ & 0,4060 & 0,4053 & 0,4087 & 0,4053 & 0,4053 & 0,4057 & 0,299 & \\
\hline
\end{tabular}

Table 3. Statistical indicators metrological characteristics of methods

\begin{tabular}{lcc}
\hline Metrological Characteristics & $\begin{array}{c}\text { Photo-colorimetric } \\
\text { technique }\end{array}$ & $\begin{array}{c}\text { Spectrophotometric } \\
\text { technique }\end{array}$ \\
\hline Convergence and accuracy & 101,17 & 99,63 \\
Gotten result, Z, \% & 4,53 & 0,83 \\
relative standard deviation, Szi, \% & 8,20 & 1,46 \\
The relative confidence interval, $\Delta z, \%$ & 4,80 & 4,80 \\
Critical for convergence results, $\Delta$ as, $\%$ & 1,07 & $-0,37$ \\
Systematic error, $\delta$ & 1,52 & 1,52 \\
Criterion uncertainty bias & & 0,9691 \\
Linearity & 1,1932 & 0,0129 \\
The angular coefficient of linear & & 2,5450 \\
dependence, b & 0,0617 & 5,1200 \\
Sb & $-17,3389$ & 1,3228 \\
Free Member linear relationship, a & 5,1200 & 0,9997 \\
The critical value for free member, a & 6,3161 & 0,9914 \\
Sa & 0,9950 & Comply or correct \\
The correlation coefficient methods, r & 0,9914 & \\
Criterion linear correlation coefficient, & does not comply & \\
Rc & & \\
Conclusion: & & \\
\hline
\end{tabular}

Table 4. Effect of $\mathrm{pH}$ on the absorption of optical density analytical solutions

\begin{tabular}{|c|c|c|c|c|c|c|c|}
\hline \multirow[t]{2}{*}{ № } & \multicolumn{3}{|c|}{ Optical density testing } & \multirow{2}{*}{$\mathrm{Sr}_{\mathrm{pH}}, \%$} & \multirow{2}{*}{$\mathrm{RSD}_{\mathrm{pH}}, \%$} & \multirow[t]{2}{*}{$\Delta \mathrm{pH}, \%$} & \multirow[t]{2}{*}{$\max \delta, \%$} \\
\hline & $\begin{array}{c}\text { Diluted hydrochloric } \\
\text { acid R }\end{array}$ & $\begin{array}{l}\text { Without } \\
\text { adding }\end{array}$ & $\begin{array}{l}100 \mathrm{~g} / \mathrm{l} \text { potassium } \\
\text { hydroxide } \mathrm{R}\end{array}$ & & & & \\
\hline 1 & 0,315 & 0,220 & 0,325 & 0,0049 & 0,484 & 1,40 & 1,52 \\
\hline 2 & 0,375 & 0,270 & 0,388 & 0,0047 & 0,467 & 1,36 & \\
\hline 3 & 0,450 & 0,320 & 0,460 & 0,0045 & 0,451 & 1,32 & \\
\hline
\end{tabular}


Table 5. The results determine the internal laboratory accuracy

\begin{tabular}{lccc}
\hline $\begin{array}{l}\text { Number of } \\
\text { model solution }\end{array}$ & $\begin{array}{c}\text { Added, } \% \\
\mathbf{X}_{\mathrm{i}}, \%\end{array}$ & $\begin{array}{c}\text { Received result, } \% \\
\mathbf{Y}_{\mathrm{i}}, \%\end{array}$ & $\begin{array}{c}\text { Received to Added } \\
\mathrm{Z}_{\mathrm{i}}=100\left(\mathrm{Y}_{\mathrm{i}} / \mathbf{X}_{\mathrm{i}}\right)\end{array}$ \\
\hline 1 & 70,00 & 71,78 & 102,55 \\
2 & & 70,79 & 101,13 \\
3 & & 71,29 & 101,84 \\
4 & 86,00 & 86,88 & 101,02 \\
5 & & 86,63 & 100,74 \\
6 & & 88,88 & 101,02 \\
7 & 100,00 & 98,76 & 98,76 \\
8 & & 98,71 & 98,51 \\
9 & & 99,26 & 99,26 \\
10 & 115,84 & 100,73 \\
11 & 116,34 & 101,16 \\
12 & 116,09 & 100,95 \\
13 & 129,70 & 99,77 \\
14 & & 129,46 & 99,58 \\
15 & 130,69 & 100,53 \\
The relative standard deviation, $\mathrm{Sr}_{\mathrm{i}}, \%$ & & 1,1199 \\
The relative confidence interval, $\Delta \mathrm{z}, \%$ & & 0,1315 \\
Systematic error, $\delta$ & & & $-0,185$ \\
Criterion uncertainty bias and error & & 1,52 \\
\hline
\end{tabular}

robasnist, convergence, internal laboratory accuracy (precision), accuracy, reproducibility.

\section{Discussion}

To assess the model error of sample preparation solutions and standard working solution were calculated theoretical values of uncertainty of analytical operations. Complete uncertainty for sample preparation photo-colorimetric and spectrophotometric methods are: $\Delta \mathrm{sp}=1,02 \%, \Delta \mathrm{sp}$ $=1,30 \%$ respectively. If validation photometric method of assay validation are first considered parameters such as stability analytical solution at the time, linearity, accuracy and convergence. The research methodology was carried out under the same conditions: in one day, in one device, by the same analyst. Check the stability of solutions was conducted for 30 minutes to 60 minutes and photo-colorimetric spectrophotometric method for analyzing the working standard solution and sample solutions. These tables indicate that the analytical solution is only stable for about 5 minutes, causing difficulties in conducting the experiment, so all the results obtained by this method for the first five minutes of cooking. Instability of analytical solutions can lead to deviations from the Beer-Lambert law and getting incorrect results. In this case, the stabil- ity of the solution is influenced by such factors: the rate of flow of a colorimetric reaction; conditions in which we determine the extent of coverage and working rooms; $\mathrm{pH}$, concentration of loratadine and reagents; Properties hydroxamate iron; change the degree of dissociation of the compound in solution dilution. So to avoid errors when using this technique has important way to prepare analytical solutions.

Analytical solution spectrophotometric method stable for hours, which is enough to determine the absorbance. To confirm the specificity of the technique relied systematic error, which made solvent and reagents, that contribution placebo. For each method measured the optical density of the solutions placebo and working standards. The values of optical densities placebo solution number 1 and standard methods for photo-colorimetric: Ablank $=0.001 ;$ Ast $=0,389$, hence $\delta$ exc $=100 \bullet 0,001 /$ $0,389=0,26 \%$. Effect placebo solution number 2 results spectrophotometric method is: Ablank $=0.001 ;$ Ast $=0,468$, $\delta$ exc $=0,21 \%$, confirming the absence of a meaningful impact on the measurement results for both techniques. To assess the linearity and accuracy were obtained 15 values of optical densities of model solutions and 4 of the optical densities for solution standard. The results are presented in the table. Calculated ratio of average 
values of optical densities for each of the 15 solutions to the mean absorbance reference solution to give value $=\mathrm{Si}$ Hui $/$ Sst $\bullet 100 \%, \mathrm{Yi}=(\mathrm{Ai} / \mathrm{Ast}) \cdot 100$. Worked in normalized coordinates, giving the concentration and analytical signal as a percentage of the nominal value. They found as the value of $\mathrm{Z}=100 \bullet(\mathrm{Yi} / \mathrm{Xi}$ ), which is found concentrations as a percentage of the administered.

The results indicate that the method photo-colorimetric do not meet modern criteria for analytical methods for quantitative determination of parameters such as stability, accuracy and linearity, so other validation parameters (robasnist, convergence and inter-laboratory precision) determined only spectrophotometric methods.

Robustness evaluation was performed taking into account the type of methodology, in this case spectrophotometric method for studying the following parameters: stability over time analytic solutions prepared by the method (described above); effect of $\mathrm{pH}$ on the stability of the optical absorption solution ethacridine. The results of studying the stability of analytical solutions spectrophotometric method for hours in the table below and demonstrate the stability of analytical solutions, inequality $\Delta \mathrm{t} \% \leq 0,32 \cdot \max \Delta \mathrm{As}=\max \delta$ performed. To study the effect of $\mathrm{pH}$ for the test solution $(85 \%, 100 \%, 115 \%)$ was added to 1-2 drops of $\mathrm{HCl}$ or $\mathrm{KOH}$ solution to play fluctuation $\mathrm{pH}$ of $\pm 10 \%$. For model solutions obtained measured optical density at the selected wavelength. Internal laboratory accuracy (precision) was assessed by the analysis of 15 samples of various model series, which was carried out in two different days and different analysts in one laboratory conditions. To prepare two different series were taken in our various sample concentration range. To prepare dilutions of these series use different measuring laboratory dishes. During the preparation of solutions and of technique was possible fluctuations in temperature, humidity, atmospheric pressure and other factors influencing the internal laboratory analysis. The technique is correct, because $\Delta \mathrm{Z}$, calculated by the ratio, the requirements: $\Delta \mathrm{Z} \% \leq \max \Delta \mathrm{As}=4,8 \%$. The method has significant bias. To examine the reproducibility of this method in terms of other laboratories, we measured the optical density of the solutions of a series of model solutions loratadine on different hardware, different days in three different laboratories. The results are presented in the table and are the results of comparing statistical deviations of three different experiments, associations and the average value of a single relative standard deviation. The resulting metrological data show that this technique can be replicated in other laboratories with confidence probability $95 \%$ deviation of the unit value of $100 \pm 1,23 \%$. The results of analysis show that this technique can be used to quantify the loratadine tablets and can be included in the quality control methods for loratadine in tablets.

\section{Conclusion}

In conclusion, we developed spectrophotometric and photo-colorimetric methods of quantitative determination of loratadine in tablets. These methods are showed good following parameters: specificity, linearity, range, accuracy (convergence) and accuracy, robasnist, the results of which revealed that spectrophotometric method can be used for the determination of loratadine in tablets and can be used for quality control of tablets.

\section{References}

1. Korobko DB, Polyauk OB, Logoyda LS, et al. Development and validation of methods for identification of loratadine tablets. Actual questions of pharmaceutical and medical science and practice. 2014; 1:55-8.

2. Ukrainian Scientific Center pharmacopoeia quality medicine. 2nd ed. Kharkiv: State Enterprise; 2014. p. 724.

3. Scientific and Expert Centre pharmacopoeia. 1st ed. Kharkiv: State Enterprise; 2008. p. 620.

4. Grizodub AI. Reproducibility of pharmacopoeial methods of spectrophotometric quantitation of medicines in different laboratories. Farmakom. 2004; 2:20-34.

5. Grizodub AI. Standard procedures validation techniques drug of quality control. Farmakom. 2006; 1-2:35-44.

6. Guidelines for the validation of methods of analysis of medicines. Moscow: 2007. p. 57. 